\title{
Emotions, intentions and their expressions: Anscombe on Wittgenstein's stalking cat
}

\author{
Valérie Aucouturier \\ Université Saint-Louis, Bruxelles \\ valerie.aucouturier@usaintlouis.be
}

Reception date: $24-1-2020$

Acceptance date: $12-5-2021$

\begin{abstract}
In this paper, I explore the difference between expression of intention and expression of emotion through a discussion of a passage from G.E.M. Anscombe's Intention, where she claims that expression of intention, unlike expression of emotion, is "purely conventional". I argue that this claim is grounded on the fact that, although emotions can be described, expressions of emotion are not descriptions at all (e.g. of some present feeling or experience). Similarly, expressions of intention are not descriptions of a present state of mind but are rather the expression of a special sort of foreknowledge of a purported action. They are, in this respect, distinct from expression of emotion, since they are a description of some future happening (the purported action). Now, the centrally descriptive character of expressions of intention is what makes them "purely conventional". But of course, Anscombe argues, one can have an intention without expressing it. And having an intention does not amount to having some description in mind.
\end{abstract}

Keywords: G.E.M. Anscombe; L. Wittgenstein; expression; emotion; intention; description; prediction

Resum. Emocions, intencions i les seves expressions: Anscombe i el gat sotjador de Wittgenstein

En aquest article exploro la diferència entre l'expressió d'intenció i l'expressió d'emoció a través de la discussió d'un passatge d'Intenció de G. E. M. Anscombe, on afirma que l'expressió d'intenció, a diferència de l'expressió d'emoció, és "purament convencional». Sostinc que aquesta afirmació es basa en el fet que, malgrat que les emocions poden descriure's, les expressions d'emoció no són descripcions de cap mena (per exemple, d'algun sentiment o experiència present). Així mateix, les expressions d'intenció no són descripcions d'un estat mental present, sinó que són l'expressió d'un tipus especial de coneixement previ d'una suposada acció. En aquest sentit, es diferencien de l'expressió de l'emoció, ja que són una descripció d'un esdeveniment futur (la suposada acció). Ara bé, el caràcter centralment descriptiu de les expressions d'intenció és el que les fa "purament convencionals». Però, per descomptat, sosté Anscombe, es pot tenir una intenció sense expressar-la. I tenir una intenció no equival a tenir una descripció al pensament.

Paraules clau: G. E. M. Anscombe; L. Wittgenstein; expressió; emoció; intenció; descripció; predicció 


\section{Summary}

1. The target: Wittgenstein's stalking cat

2. Two senses of expression: the weak and the strong

3. The natural and the conventional: ground or sophistication?

4. Emotion and intention: between expressiveness and expression
5. The descriptive character of expressions of intention

6. Conclusion

Bibliographical references

In $\$ 2$ of Intention, Elizabeth Anscombe argues against Ludwig Wittgenstein that, though we may speak of a natural expression of emotions, we cannot speak of a natural expression of intentions, since expressions of intentions are always conventional. She adds that although brutes can have intentions they cannot be said to express intentions.

Intention appears to be something that we can express, but which brutes (which e.g. do not give orders) can have, though lacking any distinct expression of intention. For a cat's movements in stalking a bird are hardly to be called an expression of intention. One might as well call a car's stalling the expression of its being about to stop. Intention is unlike emotion in this respect, that the expression of it is purely conventional; we might say 'linguistic', if we will allow certain bodily movements with a conventional meaning to be included in language. Wittgenstein seems to me to have gone wrong in speaking of the 'natural expression of an intention' (Wittgenstein, PI: \$647). (Anscombe, 1963: 5)

The elliptic character of this passage and its (at least apparently) controversial claim has attracted the attention of some readers ${ }^{1}$. Without entering the more general discussion about how the consideration of 'expressions of intention' can help us throw light on various aspects of the book, my intention here is to display the strategic character of Anscombe's reference to animals.

This is the beginning of the book. Problems are set but not yet resolved. Actually, the aim of section two of Intention is to display the unfruitfulness of starting the philosophical enquiry with the question: What is expression of intention an expression of? 'A present state of mind' (Ibid.: 2)? 'Something internal' (Ibid.: 5)? 'Foreknowledge of something future' (Wittgenstein, PI: $\$ 629)$ ? Thus, my hypothesis ${ }^{2}$ is that this passage is meant to raise a difficulty in relation to the peculiar status of 'expressions of intention' being both the expression of 'a "mind" to do something' (Anscombe, 1963: 4), and 'a descrip-

1. In particular Richard Moran and Martin Stone in their 2008 paper 'Anscombe on Expression of Intention', which goes beyond the mere understanding of the passage and constitutes a genuine key for reading Intention.

2. I have to say that this hypothesis owes a great deal to a number of discussions I have been having with Jean-Philippe Narboux. Thanks to him. 
tion of something future' (Ibid.: 5), in relation to the distinction between lying about one's intentions and not carrying out one's intentions.

Indeed, the fact that non-language-users can be said to have intentions without being able to express them can be seen as an illustration of the earlier claim that, contrary to a 'command' which 'is essentially a sign', 'an intention can exist without a symbol' (Ibid.). However, it also suggests that to have an intention is not necessarily to have 'a thought about a description' (Anscombe, 1979: 209), which would indeed involve language ${ }^{3}$. Therefore, if expressions of intention are 'descriptive', as Anscombe suggests, they are not descriptions of 'something internal'.

In the light of these suggestions, I will now outline the reasons why Anscombe would refuse to consider the mere behavioural manifestation of an intention to be an expression of intention. To do so, I will first explore a few possible misreadings of the passage and show in which way they are wrong. Thus, section one is dedicated to an exposition of Wittgenstein's original claim concerning the natural expression of an intention, which is at stake here. Even if the interest of this passage does not lie in the question of the disagreement expressed between Anscombe and Wittgenstein, its understanding depends in part on what these authors respectively understand by 'natural expression'. This is why sections 2 and 3 are dedicated to the exploration of possible understandings of 'expression' and of the distinction and relationship between the natural and the conventional. Finally (sections 4 and 5), drawing on the distinction between intention and emotion in their relation to expression, the puzzle raised by Anscombe's refusal to speak of a natural expression of intention is solved: while expressions neither of intentions nor of emotions are some kind of report of a state (of mind), contrary to emotions, intentions are not experienced. Thus, expressions of intention (which are always conventional for Anscombe) are not the linguistic manifestation of something which could otherwise be expressed (outside of a convention). Unlike expressions of emotion, they are not the mere expression of some condition, but they do describe some state of affairs, namely a future action.

\section{The target: Wittgenstein's stalking cat}

To begin with, let us have a look at the way Wittgenstein himself describes 'the natural expression of an intention' which Anscombe is willing to reject:

What is the natural expression of an intention? - Look at a cat when it stalks a bird; or a beast when it wants to escape. ((Connexion with propositions about sensations.)) (Wittgenstein, PI: \$647)

3. And which would also wrongly suggest that an expression of intention is a kind of 'report' of 'the content of one's mind' so that lying about one's intentions would be 'a false report of the content of one's mind, as when one lies in response to the query "A penny for your thoughts".' (Ibid.: 4) 
In this remark, Wittgenstein characterises the 'natural expression' with reference to animal behaviour and, arguably, to certain behaviours in general (including non-conventional primitive human behaviours). Insofar as it is a mere behaviour - i.e. non-linguistic or pre-linguistic -, the cat's behaviour is called 'natural'. Wittgenstein and Anscombe thus share the same understanding of the 'natural' as distinct from the 'conventional': 'we might say "linguistic", if we will allow certain bodily movement with a conventional meaning to be included in language' (Anscombe, 1963: 5). According to Wittgenstein, a natural expression appears to be any behaviour which makes a thought (want or attitude) manifest without the use of a convention to express it. We say the cat has the intention to catch a bird without the cat telling us that this is its intention. In a similar way, we say it is scared when it runs away from a danger.

The context of this remark in the Investigations is a criticism of the idea that intention would correspond to some sort of subjective experience that we have, as if '(for example) a particular tickle accompanied every one of my intentions' (PI: \$646). Instead, Wittgenstein argues that, e.g., to remember an intention or to realise that one had a certain intention is not to be acquainted with some kind of subjective state of mind, but rather it is to remember something about oneself in a given situation. Wittgenstein's insistence that expression of intention is visible, even in a natural, pre-linguistic, behaviour may be read as a further argument in favour of the view that an intention is not something we see or become acquainted with in our own private experience; rather, the notion is directly linked with certain characteristic behaviours or movements like the cat's stalking of a bird.

The 'connexion with propositions about sensation' suggested in Wittgenstein's remark may then be thus interpreted: we do not investigate the cat's states of mind in order to know or see that it is stalking a bird (or, say, in pain): we can just tell this from observation of its overt behaviour. Therefore, the link between a sensation and its expression and the one between an intention and its expression are, in that respect, similar: both exhibit an 'internal (logical, conceptual) relation' (Rosat, 2004: III, 45); we cannot dissociate the meaning or the understanding e.g. of 'pain'-sensation from various characteristic expressions of pain, and similarly we cannot dissociate the meaning or the understanding of 'intention' from various characteristic expressions of intention. 'What is characteristic of every expression is the existence of such an internal (logical, conceptual) relation between it and what it expresses. In that respect, there is no difference between a scream of pain and the expression of a thought, as complex and abstract as it could be' (Ibid.). Nevertheless, the fact that expressions of intention are in this respect akin to expressions of sensation and supposedly to any sort of expression, is not enough to argue for the naturalness of their expression. For instance, an expression of pain, like 'J'ai mal' ['I am in pain'], can entertain this relation to the sensation of pain and be conventional.

Still, this conception of the logical relation between an intention and its expression as internal, may lead us to argue the following in favour of Witt- 
genstein's remark: there seems to be no less reason to view the cat's stalking as a natural (primitive, non-verbal) expression of intention, than to view a scream of pain as a natural expression of pain. Should we not say, in both cases, that the non-verbal expression entertains the same sort of logical relation to what is expressed as the verbal (conventional) expression? In other words, if the link between, say, an expression of pain (like a scream or 'ouch') and pain and the one between an expression of intention and intention are of the same logical kind, then there seems to be no prima facie reason to reject the idea that the cat's behaviour (which has exactly the same sort of teleological form as human intentional action) should be considered to be an expression of intention. This is because what we see in it, after all (and Anscombe allows this - 1963: 5, 86; 1979: 209-10) is an intention; like we hear pain in a scream of pain, see fear on a scared face, etc. (Wittgenstein, RPP1: \$570; Z: \$225).

These considerations lead us to think that there must be a difference that Anscombe is indicating between the relation of intention to its expression and the relation of sensations (and, as we shall see, emotions) to their expression. It is, however, central to note that Anscombe maintains the specifically 'expressive' character of expressions of intention as a way of conjuring the claim that they would be descriptions or externalisations of some 'state of mind'.

\section{Two senses of expression: the weak and the strong}

Following some commentators, my first question will be: is there a difference in the concept of expression as it applies to emotions and intentions?

A first puzzle, which retained the attention of her readers, regards the distinction Anscombe is claiming within the field of 'expressions' between expressions of intention and expressions of emotions: 'Intention is unlike emotion in this respect, that the expression of it is purely conventional' (1963: 5). This is how Richard Moran and Martin Stone express their puzzlement:

The problem which emerges here (...) is what the relevant notion of 'expression' might be, such that it has no application to the intentions manifested by an agent's stalking movements, while still finding purchase on the non-verbal manifestations of other states like emotion. (Moran and Stone, 2008: 135)

One way of addressing the problem has consisted in distinguishing two senses of 'expression' and in claiming that one of them did not apply, according to Anscombe, to intention. There is indeed a sense of expression that we might call, following Charles Taylor (1979), the 'weak sense' of expression. 'This music expresses sadness', 'Her face expresses fear', 'I could see his joy in the way he walked to the door', 'The tone in her voice expressed her emotion', etc. are examples of this. The expressive object is not, properly speaking, doing the expressing. It is only in the eye of the observer that an attitude, a behaviour, a sound is seen as expressing something. In this weak sense of 'expression', the expressive object merely allows us to read a certain emotion, (or intention, etc.) in it; it only offers what Taylor calls 'a physiognomic reading'. 
On the contrary, 'expression' in the strong sense appears to require something more than a mere physiognomic manifestation. It requires some element of communication, a saying on the part of the expressive object or, as Donald Gustafson claims, 'a reference to subjects' (1971: 306), that is to the one(s) who express(es) whatever is expressed:

In talking I make manifest the timbre of my voice, but this is not expressed in my voice. Or again, I can make something manifest by doing something which is not at all expressive action. (...) In cases of genuine expression, the object must be said to manifest something, where this is to be attributed to the object, in a way that cannot be just reduced to its emission or utterance manifesting that something. (Taylor, 1979: 76)

I might describe the expression on your face now as 'tired'. But a tired expression is not expression in the strong sense. (...) By contrast take the smiling expression on the face of someone who is open and welcoming. The smile expresses openness, welcome. But we are now saying more than that we can read welcome in it, as we read the tiredness above. The smile communicates openness, it does not just allow it to be seen. (Taylor, 1979: 77)

Moran and Stone have proposed a similar distinction between 'expression in the impersonal sense (the manifestation of some state or condition) and expression in the personal sense (the intentional act of one person directed to another)' (Moran and Stone, 2008: 133). Based on this distinction, there has been some sort of consensus among readers that we must conclude from Anscombe's refusal to call the cat's movements an expression of intention that she denies that intentions (contrary to emotions) could ever be expressed in the weak sense. In other words, as Moran and Stone put it, she denies 'that intentions, in contrast to other states of the person, are ever impersonally expressed' (2008: 134), that is 'merely manifesting a state'; a 'strange and unintuitive doctrine', according to them.

Indeed, if the cat's stalking of a bird is to be considered to be an expression of intention, it can only be in the weak sense of 'expression', in the sense that an observer can read in the cat's behaviour (an expression of) its intention to catch the bird (Gustafson, 1971: 306). This is because, surely, when stalking a bird, the cat is not 'telling' us or anyone that it is aiming at the bird; it just is and this is what its behaviour makes manifest.

Perhaps in this passage Anscombe rejects, or rather ignores, the possibility of a weak sense of expression. However, I shall argue that her point cannot be narrowed down to this since, after all, the notion of a weak sense of 'expression' matches what she calls having an intention (precisely as opposed to expressing it):

We certainly ascribe intention to animals. The reason is precisely that we describe what they do in a manner perfectly characteristic of the use of intention concepts: we describe what further they are doing in doing something (the latter description being more immediate, nearer to the merely physical): the cat is stalking a bird in crouching and slinking along with its eyes fixed on the bird and its whiskers twitching. (Anscombe, 1963: 86) 
Her point is not that it would be irrelevant to apply the concept of 'intention' to the cat's behaviour, quite the opposite. Her point is to draw a distinction between having and expressing: 'Intention appears to be something that we can express, but which brutes (...) can have, though lacking any distinct expression of intention' (Anscombe, 1963: 5). Surely if the distinction applies to intentions, it also applies to emotions: we can have emotions and express them. They can be read in our behaviour and we can express them. To replace 'having' by 'expressing in the weak sense' or 'impersonally' appears to reduce the philosophical point to a mere word quarrel. Perhaps Wittgenstein, when talking about 'the natural expression of intention' meant 'expression' in the weak sense. However, surely Anscombe's refusal to apply the concept of 'expression' in this sense ought to concern emotions as well.

I will try to make this point clearer when considering the distinction between emotion and intention in the final section of this paper. However, before doing so, I would like to turn to a further reading hypothesis based on the distinction between the natural and the conventional and their relation.

\section{The natural and the conventional: ground or sophistication?}

If the distinction Anscombe is trying to make between expressions of intention and expressions of emotion does not depend on our understanding of the concept of 'expression' - and actually nothing points toward such a claim in Anscombe's passage - we might think it depends on her understanding of natural expression as distinct from conventional expression. Commentators have indeed suggested that her refusal to speak of a natural expression of intention was part of a refusal to consider verbal expressions of intention as grounded on some sort of primitive behaviour. This may lead us to further suggest that it is only by analogy or anthropomorphism that we apply the concept of intention to (animal) non-verbal behaviour. However, as we shall see, none of these suggestions is satisfying.

\subsection{Natural expression grounding conventional expression}

Though she does not say much about their relation, Anscombe clearly distinguishes natural expressions from conventional expressions with reference to being a language-user ('if we will allow certain bodily movements with a conventional meaning to be included in language' - Anscombe, 1963: 5). Moreover, although she reserves the 'natural expression' for considerations concerning non-speaking animals, it is not clear that she would refuse to call certain human behaviours (like a scream, for instance) 'natural expressions' (of fear, say, or pain) despite their being expressed by language-users.

According to Gustafson (1971: 302), Anscombe's understanding of Wittgenstein's notion of a natural expression of intention that she intends to reject is based on the more general view of the natural expression as being 
some sort of primitive ground for the conventional expression ${ }^{4}$. This is Wittgenstein:

Here is one possibility: words are connected with the primitive, the natural expressions of the sensation and used in their place. A child has hurt himself and he cries; and then adults talk to him and teach him exclamations and, later, sentences. They teach the child new pain-behaviour. (Wittgenstein, 1953: \$244)

Gustafson goes on to argue that based on such an understanding of the natural expression, it would indeed be 'odd' to consider the cat's behaviour as a ground for the more sophisticated verbal expressions of intention:

Now if a piece of behaviour is said to be a natural expression of intention because a linguistic practice is based on it and has some of the features of it, and because it is pre-linguistic in that it is normally replaced by verbal, conventional expression, then the notion of natural expressions of intention in animal behaviour is an odd notion. (...) On this account of it Miss Anscombe's objection is just that nothing animals do can be called natural expression of intention because their behaviour does not grow into or is not the basis for a conventional mode of expression. (Gustafson, 1971: 302)

We may be tempted by this interpretation of Anscombe's objection to Wittgenstein, since Wittgenstein himself has drawn an explicit parallel between his remark on the natural expression of intentions and 'propositions about sensations' in $\$ 647$ of the Investigations 5 .

On the other hand, contrary to Gustafson, Taylor, who will purport to defend Wittgenstein against Anscombe on this ground, reads it the opposite way:

If we wanted to define 'natural expression' as 'the natural reactions which offer the most accessible physiognomic readings which can be taken up into genuine expression in mime or style', then the actions of trying to get would certainly be the most important and central natural expressions of our desires, because so much of the quality of our motivation can be read in our action. (Taylor, 1979: 81)

Taylor understands the natural expression as something that offers a primitive physiognomic reading on which we may ground our conventions. In other words, natural expressions would be expressions on which we learn to read the same (sort of), say, emotion (e.g. sadness) as in conventional expressions. In this sense, 'the natural expression of wanting is trying to get ${ }^{6}$ ' (Taylor, 1979: 73)

4. Gustafson refers to this passage of Wittgenstein's Zettel \$541: 'But what is the word "primitive" meant to say here? Presumably that this sort of behaviour is pre-linguistic: that a language-game is based on it, that it is the prototype of a way of thinking and not the result of thought.'

5. This is the interpretation suggested by Peter Hacker (1996: 410-411).

6. Interestingly, the phrase is a transformation of Anscombe's 'The primitive sign of wanting is trying to get' (1963: 68). 
insofar as we can recognise in the movement of trying to get some manifestation of what we then conceptualise as wanting (or intending ${ }^{7}$ ):

This relation [between action and desire] is in a sense foundational for genuine expression. (...) In order to recognise reciprocally the disposition to communicate, we have to be able to 'read' each other, our dispositions and feelings have to be potentially open, in public space. Our desires have to be manifested to others, to the potential community. This is a kind of manifestation which is foundational for genuine expression, in that it is presupposed by it. This is the 'natural' level of expression, on which genuine expression builds, always with some degree of the arbitrary and the conventional. (Taylor, 1979: 89)

In suggesting that conventional or verbal expressions of intention could be grounded on some natural level of expression, Taylor, while reluctant to call these manifestations 'genuine expressions' as such, allows us to criticise Anscombe's claim that there are no natural expressions of intention. It is not as if there was some sort of unbridgeable gap between verbal expressions of intentions and animal's intentional behaviours. A passage of Wittgenstein's Remarks on the Philosophy of Psychology might suggest that he has at least been tempted to pursue the analogy:

How, to understand the order 'Throw!'; and how, the expression of intention 'Now I am going to throw'? Well - the grown-ups may perform before the child, may pronounce the word and straightway throw, - but now the child must imitate that. (...) After such-and-such language games have been taught it, then on such-and-such occasions it uses the words that the grown-ups spoke in such cases, or it uses a more primitive form of expression, which contains the essential relations to what it has previously learnt, and the grown-ups substitute the regular form of expression for the more primitive one. (Wittgenstein, RPP2: \$163)

This idea of continuity between the natural and the conventional may even lead us, on a Cavellian reading of Wittgenstein, to erase or blur the distinction between the natural and the conventional. On Cavell's account, there is a constant back and forth movement between nature and convention so that the frontier between the two is rather blurred and that, e.g., a conventional reaction may become natural. I may, for instance, have learned to say 'ouch' when I hurt myself (instead of, say, crying or screaming) and this may very well have become a natural, spontaneous, reaction:

[The conventions] are, rather, fixed by the nature of human life itself, the human fix itself, by those 'very general facts of nature' which are 'unnoticed only because so obvious', and I take it, in particular, very general facts of human nature - such, for example, as the fact that the realisation of intention requires action, that action requires movement, that movement involves

7. Anscombe would like to draw a distinction between 'merely' wanting and intending: the thing wanted is what triggers practical reasoning and intentional action. 
consequences we had not intended, that our knowledge (and ignorance) of ourselves and of others depends upon the way our minds are expressed (and distorted) in word and deep passion; that actions and passions have histories. (Cavell, 1979: 110-111)

On the ground of these interpretations, it may indeed seem that Anscombe just stipulates that the cat's behaviour is not an expression of intention and that there are no natural expressions of intention at all. This stipulation would, however, be rather surprising given her insistence that 'we certainly ascribe intentions to animals' and given her reluctance to consider that sort of ascription to be merely anthropomorphic, as illustrated by her remark that the point is 'not (...) about what may go on in the souls of cats' (Anscombe, 1963: 69).

However, contrary to those suggestions, Gustafson does not believe that, by introducing the notion of a 'natural expression of intention', Wittgenstein intended to suggest some sort of continuity between conventional and more primitive expressions. He thus offers another - as it were opposite - understanding of the distinction between the natural and the conventional.

\subsection{The natural does not take part in the convention}

Here is Gustafson's defence of a natural expression of intention:

What we understand as natural, instinctive responses have a significance to us, e.g., some of them are important, others not, because of our traditions and conventions. They are nonetheless natural for that. This is the idea of the natural contained in the concept of a natural expression. We understand the movements and sounds of some animals as fulfilling a role in their lives. Their action is given a place in accord with our conventions, even though they are not themselves, like humans, a party to these conventions. (Gustafson, 1971: 305)

In the first account of the distinction between the natural and the conventional, the natural expression was considered to be a sort of pre-linguistic manifestation that ended up being replaced by a linguistic (conventional) expression (like in the case described by Wittgenstein in \$244 of the Investigations). In this second account, the natural is understood as a non-linguistic expression but not necessarily one on which our conventional expressions are grounded.

The natural is natural in that it does not require the expressive object to participate, in the first person, in the language-game that (mostly) humans play when, say, they express their intentions. However, to be recognised as the expression it is (e.g. that of an intention to stalk a bird), it requires the observation of a creature that does participate in the conventional language-game of, say, expressing intention. According to this second sense, natural expressions are not more primitive expressions; they do not ground our more sophisticated usages of language. On the contrary, their recognition as cases of, say, the natural expression of an intention, requires a sophistication or extension 
(to the animal realm) of our more primary uses of the notions of action and intention with respect to human activities (see Gustafson, 1971: 307-308):

The concept of natural expressions of intention contains a highly sophisticated use of 'intention'. Its application probably involves some analogical considerations. It presupposes some information about the needs or desires of the creatures to whose behaviour it is applied. (...) The verbs we use in attributing natural expressions of intention have no first-person forms and none of their forms are used as agent expressions. (...) The concept of natural expression of intention - flight intention movements in a bird or the ritualized movements connected with animal courtship, for instance - is an intention concept that has application only through observation. (Gustafson, 1971: 309)

Gustafson here suggests that the natural is tainted with the conventional in the sense that we understand and recognise the natural from the point of view of our conventions - rather than in a Cavellian sense where, so to speak, our conventions become embedded in our human nature given the purposes that we may have in certain circumstances. Hence, in a sense, according to Gustafson, through the sophistication of usages the conventional expression acquires a natural form. Hence, the cat's stalking of a bird may be recognised, from the point of view of our conventions, as a case of a natural expression of intention:

[The fact that] we characterize and partially explain what people are up to by reference to intention (...) is largely dependent on the fact that people say what they are doing in acting as they do; they say what they hope to do, what they meant to do, and so on. (...) One learns the language of action and intention, and then learns to extend the concept by observation to animal behavior. (Gustafson, 1971: 300-301)

On this account, the use of a notion of intention to characterise animal behaviour is necessarily secondary: it is necessarily an extension or a refinement of our primary uses, because it can only be used in the third person, through observation.

Two remarks are needed here. First, if its aim is merely to show that we do use the concept of intention in relation to animal behaviour, Gustafson's criticism of Anscombe's refusal to talk of a 'natural expression of intention' again appears to be reduced to squabbling over words. It is as if Anscombe's distinction between 'having' and 'expressing' was purely stipulative, an arbitrary choice of words or an arbitrary restriction of the concept of expression to language (at least in the case of intentions). Second, the suggestion that the application of intention concepts to 'animal behaviour' is secondary is a rather surprising claim, even more so when attributed to Wittgenstein who notoriously tended to reject any kind of inferential account of our use of so-called 'psychological concepts' ${ }^{8}$. In other words, if it is true to say that intention-at-

8. See, e.g., Bouveresse (1987); Finkelstein (2008). 
tribution can be based on observation (as in the case of animals, or in fact of agents in general, including human agents), it does not entail that intention-attribution would be the result of some sort of inference. Actually, Anscombe's formulations suggest quite the opposite:

Just as we naturally say 'The cat thinks there is a mouse coming', so we also naturally ask: Why is the cat crouching and slinking like that? and give the answer: It's stalking a bird; see, its eye is fixed on it. (Anscombe, 1963: 87 my emphasis)

The fact that we 'naturally' speak of the cat as believing, intending, wanting, etc. suggests that this is not a deduction. Again, what goes on in the cat's head is not in question: 'We do this though the cat can utter no thoughts, and cannot give expression to any knowledge of its own action, or to any intention either' (Ibid.). In other words, it is true that verbal expression plays a specific role in our understanding of the concept of intention. This role does not, however, consist in the fact that one would need to be a language-user in order to have intentions or to act intentionally. The counterpart to this claim is that it is not by virtue of their being language-users that we attribute intentions to human agents and that their intentional behaviours or actions are not to be seen as expressions of intention at all (See Moran and Stone, 2008: 152). Indeed, 'if you want to say at least some true thing about a man's intentions, you will have a strong chance of success if you mention what he actually did or is doing' (Anscombe, 1963: 8): 'Roughly speaking, a man intends to do what he does' (Anscombe, 1963: 45). Not only does what people and animals do usually show their intentions, but also intentions do not have to be 'far removed' from what they are presently doing (as a distant objective could be). There must, therefore, be some further reason, other than the mere restriction of the concept of expression to convention, for refusing to call intentional action an expression of intention. Let us explore one last hypothesis based on an exegesis of Wittgenstein.

\section{Emotion and intention: between expressiveness and expression}

In a conference on Wittgenstein on expression (2004), Jean-Jacques Rosat argues against Peter Hacker that there is no direct continuity between the kind of avowal an expression of emotion is and the kind of avowal an expression of intention is:

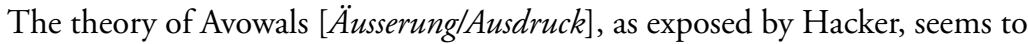
me to rely on a confusion between to express in the sense of a verbal formulation, a declaration of something (which can be done in a completely inexpressive manner) and to express in the sense of having an expressive behaviour or discourse; that is a discourse which, through the choice of words, the tone of voice, etc., is an analogue of, a substitute for, or the extension of an expressive behaviour. (Rosat, 2004: 43 - my trans.) 
Rosat's distinction between expression and expressiveness does not overlap Taylor's distinction between a weak and a strong sense of 'expression', or Moran and Stone's distinction between expression in the personal and in the impersonal sense. Rather, it suggests that the sense in which, say, a face can be said to express sadness, is utterly different from the sense in which 'I am going to take a walk' may be said to express my intention to take a walk. The kind of avowal at stake in the case of emotion appears to be utterly different from the kind of avowal at stake in the case of intention:

If I scream 'I'm scared!' when facing a spider, my use of this verbal expression is rather similar to my jumping and screaming 'Oh!'. But if, when asked 'What are your plans for tonight?', I reply 'I intend to go to the cinema.', I am doing something else than just expressing my love for cinema or making the first step to the cinema: I inform my hearer of my project. There is nothing expressive here. (Rosat, 2004: 43-44 - my trans.)

The distinction points to the specifically expressive character of the exclamation of fear, whether verbal or not, conventional or not, as opposed to the rather informative (or predictive, as Anscombe says - 1963: 3) character of an expression of intention. Now, when Anscombe points at the crucially conventional character of expression of intention that distinguishes it from expression of emotion, she is making a similar move to the one Rosat is making here: she is pointing at a crucial difference between one sort of expression that applies to emotion and that does not apply to intention. We may talk about the natural expression of emotions because our discourses about emotions have this feature of being built on the peculiar expressiveness of our behaviour, face, etc. '?

'We see emotion.' - As opposed to what? - We do not see facial contortions and make the inference that he is feeling joy, grief, boredom. We describe a face immediately as sad, radiant, bored, even when we are unable to give any other description of the features. - Grief, one would like to say, is personified in the face. This is essential to what we call 'emotion'. (Wittgenstein, RPP2: $\$ 570$; cf. $Z$ : $\$ 225$ )

Expressiveness or expression in the weak sense is part of our concepts of emotion. My movements or my action cannot, however, be said to be expressive of my intention in the sense my face expresses fear. There is no such characteristic 'repertoire' of natural manifestations of, say, intending to take a walk. The notion of an expression of intention does not imply expressiveness in the sense the notion of expressions of fear, anguish, etc. do. We find a similar remark in Moran and Stone:

9. 'We think of the utterance of an emotion as though it were some artificial device to let others know that we have it. Now there is no sharp line between such "artificial devices" and what one might call the natural expressions of emotion. Cf. in this respect: $a$ ) weeping, $b$ ) raising one's voice when one is angry, $c$ ) writing an angry letter, $d$ ) ringing the bell for a servant you wish to scold.' (Wittgenstein, $B B: 103$ ) 
It seems natural to speak contrastingly of natural and conventional 'expressions' of, say, fear, precisely because, in this case, conventional expression can take up or perform the same work as natural expression - there is no gap. (...) The other's frightened look and his 'I'm afraid' can convey the same thing his fear. This isn't to say that natural expressions of fear are given to another or meant to inform him. But conventional expressions of fear are not always given either. When they are, however - and this is what matters here - what they overtly convey is what might also be read in the speaker's non-linguistic behaviour. Verbal expressions of intention, in contrast, do not ever stand in for intentional behaviour in this way. (Moran and Stone, 2008: 154)

We may thus shed light on this difference by noticing that expressive behaviours (like emotions) - be they natural or conventional - may be expressions both in the weak sense (my tone of voice and my shaking hands may express anguish, though $I$ do not really - intend to - express my anguish) and in the strong sense (I may indeed want to express my anguish, or my fear, or my pain, etc.). There are, so to speak, typical 'natural' expressions of (at least) certain emotions. There is 'no gap' between the natural and the conventional in the case of emotions. On the contrary, we do not find any equivalent of a natural expression (that would do, so to speak, the same job as the verbal/ conventional expression) in the case of intention. On that account there is no natural expressive form of intention.

This difference sheds light on the distinction Anscombe proposes between expressions of emotions that are expressive in a sense that expressions of intention are not: although we may read intentions through other people and animals' behaviours, a mere behaviour ('bodily movements with a conventional meaning' being excluded) can never play the role of the expression of an intention. The difference between emotion and intention with respect to their expression lies in the fact that emotion-like expressive behaviours (either natural or conventional) can be expressions in the weak sense (like a face expresses fear) and in the strong sense (e.g. if one says 'I'm scared'). There would therefore be typical natural expressions of (at least some) emotions - independently of the question of knowing whether they are grounding conventional expressions or whether they are sophistications of them. With emotions, there does not seem to be any gap between the natural and the conventional expression. Emotions are expressive in a sense that intentional behaviours and actions are not.

So far, I distinguished expression in the weak sense and expression in the strong sense. An expression in the strong sense amounts to 'saying' (Taylor, 1979) something (though 'saying' is a bit too narrow), i.e. participating in the first person in a language-game (Gustafson, 1971) or expressing in the personal sense' (Moran and Stone, 2008). On the contrary, an expression in the weak sense is a manifestation that does not involve the expressive object as agent but only what can be read or observed in its behaviour (Taylor); the expressive object participates in the third person in a language-game (Gustafson); (s)he/it expresses 'in the impersonal sense' (Moran and Stone). 
We saw that both Taylor's and Gustafson's defences of Wittgenstein rely on their respective understanding of the notion of a natural expression of intentions. They both claim that we may talk of an expression in the weak sense, insofar as some intentional behaviour may allow us to read an intention in it, through observation. According to Gustafson, we do so through a sophistication of our notion of intention by extending its application to the animal realm. According to Taylor, typical primitive behaviours (like trying to get) can be said to be natural expressions of intentions by virtue of their grounding our language game of intentional action (just like natural expressions of emotions or pain may ground our language game concerning them).

Anscombe, however, rejects this claim by saying that animals may be said to have intentions but not to express them. Whereas Gustafson equates 'expressing' (in the weak sense) and 'having', Anscombe does not. In that respect, she insists, intention differs from emotion. I suggested that this difference may lie in the peculiar mode of expression of emotions (or rather their expressiveness) that does not characterise expressions of intention. Indeed, whereas a natural expression of emotion may play the exact same role as the conventional expression (in the weak or in the strong sense), this is not the case of so-called natural expressions of intentions. So far, we are left with the following assertion: a mere intention-behaviour is not as such an expression. A consequence of this seems to be that there is no sense in which my action (my behaviour) or anyone else's can be said to express my intention(s). Again, the behaviour of a cat stalking a bird cannot express intention in the sense a scream expresses fear.

The distinction between expressiveness and expression seems promising. Emotions and intentions do have something in common. They are or can be expressed. To that extent, they are not to be understood as descriptions or reports of the content of one's mind. We simply have them and sometimes we express them. When we have (or experience) an emotion, our behaviour may or may not display that emotion. When we have an intention, our behaviour may or may not display that intention. However, while we speak about feeling or experiencing an emotion, we do not speak about 'experiencing' an intention. Neither expressions of belief, nor expressions of intention are accompanied by any particular experience or feeling or sensation:

'I intend' is not an expression of an experience. There is no cry of intention, any more than there is one of knowledge or belief. (Wittgenstein, RPP2: \$179)

Moreover, 'there is no bodily expression typical of belief' (Wittgenstein, RPP2: $\$ 134$ ) any more than of intention ${ }^{10}$. This is an important difference between emotions, on the one hand, intentions and belief, on the other ${ }^{11}$.

10. 'As Wittgenstein himself notes, there isn't any distinctive behavioural repertoire of intentional action, as there is of emotional states and feelings.' (Moran and Stone, 2008: 154 about the above quote from Wittgenstein)

11. 'Intent, intention, is neither an emotion, a mood, nor yet a sensation or image. It is not a state of consciousness. It does not have genuine duration.' (Wittgenstein, RPP2: $\$ 178 ; Z$ : 45) 
However, it also suggests a difference between 'merely' wanting and intending, to the extent that wanting can be related to some feeling of desire, while intending is not a feeling at all ${ }^{12}$; no 'tickle' accompanies my intentions.

Hence, expressions of emotions are not reports or descriptions of some feeling or experience, and to that extent there is continuity between having and expressing emotions (either naturally or through convention). However, emotions, like pain and contrary to intention, are felt and experienced and, in this respect, can be described. An expression of emotion is an expression of a feeling. An expression of intention is not. But expressions of emotions are not, as such, descriptions of anything. They are the manifestation of a feeling (which, in turn, can be described). On the other hand, while the cat's behaviour is said to be a manifestation of its intention to catch the bird, it is not the expression of a feeling (which, in turn, could be described).

Expressions of intention are not reports or descriptions of some feeling or experience either. Furthermore, there is an important sense in which having (manifesting) an intention is expressing it. However, contrary to expressions of emotions, expressions of intention are descriptions, not of an experience or a state of mind, but of a future happening. This descriptive character of expressions of intention (that they share with expressions of beliefs and opinions ${ }^{13}$ ), and actually their predictive character - their ability to inform my hearer of my project' (Rosat, 2004: 43) - is moreover what distinguishes them from expressions of emotions and what ties them to language, as the last section of this paper will show.

\section{The descriptive character of expressions of intention}

Section two of Intention, of which the quote we are dealing with is the final paragraph, stands as an abortive attempt to provide a philosophical distinction between an expression of intention and a prediction which does not merely rest on our 'intuitive' understanding of ordinary language:

If (...) we ask in philosophy what the difference is between e.g. 'I am going to be sick' as it would most usually be said, and 'I am going to take a walk' as it would most usually be said, it is not illuminating to be told that one is a prediction and the other the expression of an intention. (Anscombe, 1963: 2)

The suggestion put forward by Anscombe at the beginning of the book, in favour of which she will in fact argue at the very end of the book, is that an expression of intention is not (at least not merely) 'the description - or expres$\operatorname{sion}^{14}$ - of a present state of mind' (Anscombe, 1963: 2), but rather (like an

12. See Anscombe's considerations about 'The primitive sign of wanting is trying to get' (1963: 68).

13. Which are not reports of the content of one's mind but descriptions of some state of affairs.

14. As we shall see, when it comes to this first suggestion, the distinction between 'description' and 'expression' is relevant. 
order or an imperative) 'a description of some future action' (Ibid.: 3) or of a 'proposed action' (Ibid.: 91). It is 'essentially connected with the future' (Ibid.) and provides 'information' about what will happen in the future. In fact, this characteristic affiliates it to predictions (estimates) and commands, although it is 'in no sense an estimate of the future founded on evidence, nor yet a guess or a prophecy' (Ibid.: 3). Hence, 'adopting a hint from Wittgenstein ${ }^{15}$ (PI: $\$ 629-30)$ ', Anscombe ends up suggesting that we consider 'expressions of intention' as a kind of prediction in the broad sense:

A man says something with one inflection of the verb in his sentence; later that same thing, only with a change of inflection of the verb, can be called true (or false) in face of what has happened later. (Anscombe, 1963:2)

On this account, Anscombe continues, 'commands, expressions of intention, estimates' can be said to be kinds of predictions. They express or are meant to express what Wittgenstein calls 'foreknowledge of the future' (PI: $\$ 629$ ). That is to say, they provide 'information' about what will happen in the future:

The indicative (descriptive, informatory) character is not the distinctive mark of 'predictions' as opposed to 'expressions of intention', as we might at first sight have been tempted to think. (Anscombe, 1963: 3)

This remark will lead Anscombe to consider ${ }^{16}$ expressions of intention (and even commands) as genuine descriptions of future actions (or states of affairs). To call them descriptive here is to suggest that they are liable to be true or false. The suggestion that they belong to the family of predictions (i.e. statements about the future) is moreover the suggestion that they are liable to be true or false as regards what happens and not merely as regards what one has in mind.

In order to clarify this crucial distinction, we may extract from section two the observations in favour of calling expressions of intention kinds of predictions and the objections against this. Examining the objections will help us clarify the claim that expressions of intention are a kind of prediction.

\subsection{Truth}

The first objection to calling an expression of intention a kind of prediction is the following:

If I do not do what I said I would, I am not supposed to have made a mistake, or even necessarily to have lied; so it seems that the truth of a statement of intention is not a matter of my doing what I said. (Ibid.: 4)

15. Who says something similar to the passage just quoted: "I am going to take two powders now, and in half-an-hour I shall be sick" - It explains nothing to say that in the first case I am the agent, in the second merely the observer'. (PI: $\$ 631$ )

16. Probably against the position which was, in her time, called 'ascriptivism'. See Geach (1960). 
The objection is that I can truly say what I intend to do and still not do what I said ${ }^{17}$. It therefore seems that the truth of my statement of intention and my doing what I said are two distinct matters. In addition, the concept of a mistake here seems to be misplaced if it aims to suggest that the evidence on which I ground my statement can be flawed in the same fashion as the evidence on which one grounds an estimate can be flawed. Indeed, like other kinds of expressive statements, an expression of intention is neither based on evidence, nor hypothetical: one does not notice one's intentions, one has them; this is why we would rather speak of an expression or a declaration of intention than of the description of an intention. As we already noted, the register of 'expression' as distinct from the register of 'description' is what makes intention akin to emotions and distinct from estimates and commands ${ }^{18}$. Whether or not I do what I said, one would not say what I said was a mistake if I do not act accordingly. In this respect, the truth of an expression of intention seems to be a matter of truthfulness or sincerity ${ }^{19}$. Although, and this is crucial, 'there are other ways of saying what is not true, besides lying and being mistaken'.

If an expression of intention is a lie, however, 'what I say is a lie because of something present, not future' (Ibid.). This would, though, also apply to the expression of my belief or my estimate that 'it will rain in an hour' or that 'I am going to be sick', since:

A lie is an utterance contrary to one's mind, and one's mind may be either an opinion, or a mind to make something the case. (Ibid.: 4)

In other words, the possibility of a lie here does not undermine the fact that an expression of intention is about some future happening, unless we are ready to suggest that an estimate is the mere expression of someone's present opinion and does not engage the future. I could lie as well about some present knowledge, which would not undermine the fact that my statement was meant to say what the case is. The important points here are (1) that the possibility of a lie does not undermine the expression of intention's relation to the future and (2) that to lie about one's intention is not to provide 'a false report of the content of one's mind, as when one lies in response to the query "A penny for your thoughts"' (Ibid.: 4).

Before turning to (1), one last word about (2): this later remark confirms that an expression of intention is not a report or a description of a state of mind or a thought that would occur to me. Neither is an estimate. However, expressions of intention, like estimates, are descriptions of some future happening, as the following example illustrates:

17. These remarks are to be related to section 45 of Intention where Anscombe disputes the possibility for 'my knowledge' of what is done to be 'independent of what actually happens' (Ibid.: 82).

18. Although, as we shall see, an expression of intention can describe a state of affairs.

19. Insofar as their sincerity can be questioned, we would perhaps more naturally talk about pretence in the case of emotions. However, someone can lie when saying 'I am scared' or 'I am happy for you'. 
Nor can we say: But in an expression of intention one isn't saying anything is going to happen! Otherwise, when I had said 'I am just going to get up', it would be unreasonable later to ask 'Why didn't you get up?' I could reply: 'I wasn't talking about a future happening, so why do you mention such irrelevancies?' (Ibid.: 92)

Although they both relate to what happens - or rather what will happen - the relation of an expression of intention and the relation of an estimate to what happens are rather different. It is though interesting to note already that they both relate to some future happening. This is why "I intend to go for a walk but shall not go for a walk" does sound in some way contradictory" (Ibid.: 5). If ' $I$ intend to go for a walk' expresses my intention to go for a walk and 'I shall go for a walk' is conjecturing that I will do so, both sentences are statements about what I will do, my future action, although the grounds on which I tell them are different. To paraphrase a later passage of Intention on the knowledge of one's own intentional action (Anscombe, 1963: 51): they are two ways of relating to the same 'object', to 'exactly the same thing' (my going for a walk, i.e. my future action under this very same description) ${ }^{20}$ :

If I say I am going for a walk, someone else may know that this is not going to happen. It would be absurd to say that what he knew was not going to happen was not the very same thing that I was saying was going to happen. (Ibid.: 92 - second emphasis is mine)

In other words, expressions of intentions are predictions in that they provide information about some future happening. Their difference with estimates seems to lie in the fact that they cannot be mistaken in the same way:

In some cases the facts are, so to speak, impugned for not being in accordance with the words, rather than vice versa. This is sometimes so when I change my mind, but another case of it occurs when e.g. I write something other than I think I am writing: as Theophrastus says (Magna Moralia, 1186b 22), the mistake here is one of performance, not of judgement. (Ibid.: 4-5)

As we saw, 'if I do not do what I said I would, I am not supposed to have made a mistake'. That is to say, I am not supposed to have misjudged or misreported my own intentions, because, to the extent that I am the one to decide what they are, such a mistake is logically impossible in relation to my own intentions. Similarly, of course, an estimate cannot be a mistaken report of one's own opinion or belief. However, what one says can be false because one misjudged the facts or the evidence. On the contrary, an expression of intention is not at all based on evidence. It is not a hypothesis as to what

20. It would perhaps be careless here to speak of the knowledge of exactly the same thing (practical on the one hand and hypothetical on the other), as Anscombe does when speaking about practical knowledge proper (of my present - not future - action), but prefers not to when addressing this quasi-contradiction (see 1963: \$52). What is important here is that the object of intent or belief - as she would rather call them - is the same. 
will probably happen. In this respect, expressions of intention are closer to commands:

The reasons justifying an order are not ones suggesting what is probable, or likely to happen, but e.g. ones suggesting what it would be good to make happen with a view to an objective, or with a view to a sound objective. In this regard commands and expressions of intention are similar. (Anscombe, 1963: 4)

To the extent that expressions of intentions are justified by 'reasons to do' or 'reasons for acting' rather than 'evidence' or reasons for believing or thinking something will happen (Ibid.: 6), they are liable to a specific kind of mistake - which would indeed undermine the truth of what is said: namely 'mistake in performance' as distinct from 'mistake in judgement'. There is no room for considerations about these distinctive kinds of mistake ${ }^{21}$ which would not be directly relevant to the present topic. However, we may note that they are only one way among others to consider how truth relates to both kinds of statements. Changing one's mind or being prevented are two other ways in which a (truthful) expression of intention can end up being untrue. The key point here, without entering into detail, is that, in both cases, 'what I said was not true'. However, in the case where 'I don't do what I said', 'the facts are (...) impugned for not being in accordance with the words, rather than vice versa' (Ibid.: 4-5), because the point is to 'make happen' or 'make true' what one said rather than wait and see whether one's saying is confirmed to be true.

This crucial and special relation of expressions of intention with what happens (or will happen) shows the earlier objection of expressions of intention being indifferent to future happenings to be wrong. They can be called predictions to the extent that they are descriptions of some future happening and that their truth (as distinct from their truthfulness) depends on it. This descriptive character of expressions of intention constitutes the key difference with expressions of emotion.

\subsection{Existence and expression}

We may now turn to the second objection to calling an expression of intention a prediction or rather to the second 'reason for the very natural idea that in order to understand the expression of intention, we ought to consider something internal, i.e. what it is an expression of' (Ibid.: 5):

A command is essentially a sign (or symbol), whereas an intention can exist without a symbol; hence we speak of commands, not of the expression of commanding; but of the expression of intention. (Ibid.: 5)

21. There is an important literature on this topic which concerns the concept of 'practical knowledge'. See, e.g., Descombes (2002); Özaltung (2016); Ford et al. (2008). 
'An intention can exist without a symbol'. One can have an intention without expressing it. This is the objection raised in the first quote of this paper. If we can distinguish the intention from its expression, it seems we can focus on the intention itself as 'a purely interior thing' (Ibid.: 9), what the expression of intention is an expression of. This calls for a few remarks.

First, there is something that an expression of intention is supposed to be an expression of. However, it does not have to be 'something internal', a 'feeling' or a 'thought'. Second, 'having' an intention, as illustrated by the cat example, is not reduced to 'a purely interior thing' - which would be the case when 'a man (...) form $[\mathrm{s}]$ an intention which he then does nothing to carry out' (Ibid.: 9). The two cases of 'having' an intention are different. On the one hand, the cat is supposedly only capable of having intentions, not of expressing them. On the other hand, the man withholding his intention is both capable of having intentions and of expressing them. It is for this very reason that, in the man's case, we can conceive of his intention as remaining a purely interior thing: a thought he has but does not express, but a thought he could express. For instance, he could still at some point reveal his intentions. Meanwhile, it would be conceptually more difficult to think of the cat as having intentions it would not share.

\section{Conclusion}

With these considerations in mind, we may now turn back to the exegesis of the opening paragraph.

Remember that the example illustrates a difference between intentions and commands: 'A command is essentially a sign (or symbol), whereas an intention can exist without a symbol' (Anscombe, 1963: 5). 'An intention can exist without a symbol' is reformulated in the following way:

Intention appears to be something that we express, but which brutes (which e.g. do not give orders) can have, though lacking any distinct expression of intention. (Ibid.)

We are now in a position to say that the distinction Anscombe introduces between having and expressing is not one which concerns the truthfulness or sincerity of an expression. She is not considering the case of intention remaining 'a purely interior thing'. She is considering the case of having an intention which is manifested in one's intentional action (or behaviour) but not stated, declared or expressed. We moreover saw that, to that extent, the fact that the agent is a cat rather than a human being is indifferent to the fact that its behaviour is not an expression of intention.

The refusal to call an intentional action the expression of the agent's intention is because an expression of intention is not the manifestation of a state, or feeling, or emotion. On the contrary, the expression of emotion is linked to the emotion as a kind of reaction to a feeling or experience. The idea of a natural expression emphasises the idea of a reaction. 
Indeed, intentions are not any kind of experience or state. This is why we may speak of a natural expression (reaction or manifestation) of a feeling or emotion, but not of a natural expression of intention. That is not to say, however, that one cannot have intentions (in action) without expressing them, which is quite common. Having intentions does not depend on being a language user. In fact, we have intentions, i.e. we do act intentionally, before learning to express them in language.

However, what really distinguishes emotions from intentions is that there is a concept of truth that applies to expressions of intention and not to expressions of emotions. Indeed, expressions of emotions are not said to be true or false on being accurate reports or descriptions of a state but rather, as we saw, on being truthful or untruthful, sincere or insincere. Likewise, expressions of intention are not said to be true or false reports or descriptions of a state; however, they are true or false descriptions of a future happening. Hence, an expression of emotion is not a description at all, while an expression of intention is a description of a future happening (an action). Therefore, having an intention is not at all expressing an intention, to the extent that an intentional behaviour (or action) is neither true nor false in itself, although it can be pretence of a sort (like expressions of emotions).

The predictive character of expressions of intention, their being descriptions of a future action, relates them to practical knowledge:

Why do I have doubts about his intention, but not about mine? To what extent am I indubitably acquainted with my intention? What, so to speak, is the use of my knowing my intention? That is, what is the use, the function, of the expression of intention? That is, when is something an expression of intention? Well, when the act follows it, when it is a prediction. I make the prediction, the same one as someone else makes from observation of my behaviour, without this observation. (Wittgenstein, RPP1: \$788; 140)

Expressions of intention are not the manifestation of an internal state. They are the expression of a kind of 'foreknowledge'. They are predictions. They are to practical knowledge as observational knowledge is to estimates, opinions or beliefs about the future. Expressions of intention are expressions of a knowledge the truth of which revolves around the actual performance of an intentional action. This is the sort of truth Anscombe elsewhere calls (following Aristotle) 'practical truth'. Of course, 'the cat can utter no thoughts, and cannot give expression to any knowledge of its own action, or to any intention either.' (Anscombe, 1963: 87). However, although one can have knowledge and intentions without expressing them, this does not undermine the claim that non-speaking animals have intention and knowledge, quite the opposite:

When a dog smells a piece of meat that lies the other side of the door, his trying to get it will be his scratching violently round the edges of the door and snuffling along the bottom of it and so on. Thus there are two features present in wanting; movement towards a thing and knowledge (or at least opinion) that the thing is there. When we consider human action, though it is a great 
deal more complicated, the same features are present when what is wanted is something that already exists. (Anscombe, 1963: 68-69- my emphasis)

Of course, the knowledge in question is not 'practical knowledge'. The remark here does, however, show that the point is not to refuse the application of such concepts to animals, or rather to certain typical behaviours. In fact, the example supports the point that to have an intention is not necessarily to have a description in mind, as illustrated by the following example:

Animals that have no language can have intentions too: how then, it is asked, can it be right to say that an intention is always 'under a description'? (...) I suppose that the one who offers [this objection] must be taking it was intentional under this description, not that' to imply that the first description is in some sense written into something inside the agent. (...) It sounds as if the agent had a thought about a description. But now let's suppose that a bird is landing on a twig so as to peck at bird-seed, but also that the twig is smeared with bird-lime. The bird wanted to land on the twig all right, but it did not want to land on a twig smeared with bird-lime. (...) This way of talking does not presuppose that the bird has any thoughts about descriptions. (...) $[S]$ omeone who says the bird's action was intentional (or voluntary) under one description, not under the other, need not enter into that dispute at all. (...) That the bird is not a language-user has no bearing on this. (Anscombe, 1979: 209-210)

In light of this remark, we may confirm that an expression of intention is not the expression of a thought as in the phrase 'a penny for your thoughts'. It is an expression of a kind of predictive knowledge, which is not based on observation or evidence, but rather on the agent's position to make it true.

An extension of the current investigation would be its relation to practical knowledge as such, and more specifically to the concept of practical truth about which Anscombe says the following:

Practical truth is truth created by action in a sense in which neither branches, nor dogs, nor children are capable of action. (Anscombe, 2005: 157)

However, this is another story, since the exclusion here of branches, dogs and children is not based on their supposed inability to make some description of their intentional action true, i.e. to act intentionally or voluntarily. It is rather a way of pointing to their inability to aim at the good qua good.

\section{Bibliographical references}

Anscombe, G.E.M. (1963 [1957]). Intention, $2^{\text {nd }}$ edition. Oxford: Basil Blackwell. - (1982 [1979]). "Under a Description". In: Metaphysics and the Philosophy of Mind: Collected Philosophical Papers II, 208-219.

- (2005 [1993]) "Practical Truth". In: M. Geach and L. Gormally (eds.). Human Life, Action and Ethics. St Andrews, Charlottesville: St Andrews Studies in Philosophy and Public Affairs, 149-167. 
Bouveresse, J. (1987). Le mythe de l'intériorité. Paris: Minuit.

Cavell, S. (1979). The Claim of Reason. Oxford: Oxford University Press.

Descombes, V. (2002). “Comment savoir ce que je fais?”. Philosophie, 76, 15-32.

Finkelstein, D. (2008). Expression and the Inner. Cambridge MA: Harvard University Press.

Ford, A.; Hornsby, J. and Stoutland, F. (eds.) (2011). Essays on Anscombe's Intention. Cambridge, MA: Harvard University Press.

Geach, P. (1960). "Ascriptivism”. The Philosophical Review, 69 (2), 221-225.

Gustafson, D. (1971). "The Natural Expression of Intention". The Philosophical Forum: A Quarterly, II/3, 299-315.

Hacker, P. (1996). Wittgenstein, Mind and Will, Part. II. Oxford: Blackwell. Moran, R. and Stone, M.J. (2008). "Anscombe on Expression of Intention". In: C.S. SANDis. New Essays in the Philosophy of Action. New York: Palgrave Macmillan, 132-168.

Özaltung, E. (2016). "Practical Knowledge of What Happens: A Reading of $\$ 45 ”$. Klesis, 35.

Rosat, J.-J. (2004). "Description et expression". Dix conférences sur Wittgenstein et la description de l'expérience [online, 15 June 2009]. Retrieved from $<$ http://www.college-de-france.fr/default/EN/all/laboratoire_philolangage_fr/textes_de_jeanjacques_rosat.htm $>$.

TaYlor, Ch. (1979). "Action as expression”. In: C. Diamond and J. Teichman (ed.). Intention and Intentionality: Essays in Honour of G.E.M. Anscombe. N.Y., Ithaca: Cornell University Press, 73-89.

Wittgenstein, L. (2001 [1953]). Philosophical Investigations [PI], trans. G.E.M. Anscombe. Oxford: Blackwell.

- (1965 [1958]). The Blue and the Brown Books [BB]. New York: Harper \& Row.

- (1967). Zettel [Z], E. Anscombe and G.H. Von Wright (ed.), trans. E. Anscombe. Oxford: Blackwell.

- (1980a). Remarks on the Philosophy of Psychology, vol. 1 [RPP1], trans. G.E.M. Anscombe. Oxford: Blackwell.

- (1980b). Remarks on the Philosophy of Psychology, vol. 2 [RPP2], trans. C.G. Luckhardt and A.E. Aue. Oxford: Blackwell. 
Valérie Aucouturier is professor of contemporary philosophy at Université Saint-Louis - Brussels and member of the Centre Prospéro. Langage, Image, Connaissance. Her research work lies at the crossroads of several fields of philosophy: philosophy of mind and of psychology, philosophy of action and philosophy of language. She is the author of Lintention en action (Vrin, 2017), Qu'est-ce que l'intentionalité? (Vrin, 2012), Elizabeth Anscombe. L'esprit en pratique (CNRS Editions, 2012), and the editor of a number of journals and books including Lectures contemporaines de Elizabeth Anscombe (Klesis 35, 2016) and (with Marc Pavlopoulos) Agir et penser: essais sur la philosophie d'Elizabeth Anscombe (Publications de la Sorbonne, 2015).

Valérie Aucouturier és professora de filosofia contemporània a la Universitat Saint-Louis de Brussel-les i membre del Centre Prospéro. Langage, Image et Connaissance. El seu treball de recerca se situa a la cruilla de diversos camps de la filosofia: filosofia de la ment i de la psicologia, filosofia de l'acció i filosofia del llenguatge. És autora de L'intention en action (Vrin, 2017), Qu'est-ce que l'intentionalité? (Vrin, 2012) i Elizabeth Anscombe. L'esprit en pratique (CNRS, 2012), i editora de diverses revistes i llibres, com «Lectures contemporaines de Elizabeth Anscombe» (Klesis 35, 2016) i, amb Marc Pavlopoulos, Agir et penser: essais sur la philosophie d'Elizabeth Anscombe (Publications de la Sorbonne, 2015). 